\title{
PRÁTICAS SUSTENTÁVEIS EM ORGANIZAÇÕES MILITARES: VIABILIDADE ECONÔMICA E BENEFÍCIOS AMBIENTAIS NA IMPLANTAÇÃO DE PROJETOS DE ENERGIA SOLAR.
}

\author{
SUSTAINABLE PRACTICES IN MILITARY ORGANIZATIONS: \\ ECONOMIC FEASIBILITY AND ENVIRONMENTAL BENEFITS IN \\ THE IMPLEMENTATION OF SOLAR ENERGY PROJECTS \\ Alberto Jorge de Souza Júnior ${ }^{1}$ \\ Wanderlei José Ghilardi ${ }^{2}$ \\ Sérgio Rossi Madruga ${ }^{3}$ \\ Samia Mercado Alvarenga ${ }^{4}$
}

Bacharel em Ciências Contábeis pela

Universidade Federal de Santa Maria (UFSM).

Doutorado em

Desenvolvimento Regional pela Universidade de Santa Cruz do Sul - UNISC (2011). Mestrado em Administração pela Universidade Federal de Santa Maria - UFSM (2006). Especialização em Controladoria e Finanças pela Universidade Federal de Santa Maria (2001)

Doutor em Administração, Programa de Pós-Graduação em Administração, Área Administração, FEA/ USP - Universidade de São Paulo - São Paulo (2014). Mestre em Administração pela Universidade Federal de Santa Catarina (2001) Atua principalmente nos seguintes temas: implantação de sistemas de custeio, sustentabilidade controladoria e gestão e educação ambiental.

Doutoranda em Economia na Universidade Federal de Minas Gerais (UFMG). Mestra em Economia pela Universidade Federal de Sergipe (UFS) Graduada em Ciências Econômicas pela Universidade Federal de Santa Maria (UFSM).
RESUMO: Frente ao contexto de degradação ambiental e escassez de recursos naturais, as energias renováveis emergem como uma alternativa ambientalmente limpa. Nesse sentido, no Brasil, a crise hídrica e o aumento das emissões de gases de efeito estufa faz com que a energia solar ganhe espaço inclusive no setor público. Este trabalho objetiva quantificar os custos com a implantação de um sistema fotovoltaico de modo a analisar a viabilidade econômica bem como os benefícios ambientais decorrentes da instalação de projetos de geração de energia solar nas Organizações Militares de Santa Maria - RS. Para tanto, adotou-se o método descritivo de caráter quantitativo que envolve a coleta e análise de dados e cálculos de viabilidade de projetos, estimavas de tempo de retorno do investimento e projeções relativas as emissões gases de efeito estufa. Os principais resultados sugerem que a economia de energia gerada após a instalação dos projetos, pode no longo prazo, compensar os custos iniciais com investimentos. No que se refere ao tempo de retorno, quando considerada a vida útil do equipamento, a viabilidade econômica foi corroborada. Por fim, as projeções apontam para níveis consideravelmente menores de poluentes.

PAlAVRAS-Chave: Energia solar; Viabilidade; Sustentabilidade.

ABSTRACT: Against the backdrop of environmental degradation and scarcity of natural resources, renewable energy emerges as an environmentally clean alternative. In Brazil, the water crisis and the increase of emissions of greenhouse gases causes that the solar energy gains space even in the public sector. The objective of this work is to quantify the costs with the implementation of a photovoltaic system in order to analyze the economic viability as well as the environmental benefits resulting from the installation of solar energy generation projects in the Military Organizations of Santa Maria - RS. In order to do so, we adopted the quantitative descriptive method that involves the collection of data analysis as well as calculations of feasibility of projects, estimated time of return on investment and projections related to greenhouse gases. The main results suggest that the energy savings generated after the installation of the projects can, in the long run, offset the initial investment costs. Regarding the time of return, when considering the useful life of the equipment, the economic viability was corroborated. Finally, projections point to considerably lower levels of pollutants.

KEYWORDS: Solar energy; Viability; Sustainability. 


\section{INTRODUÇÃO}

A energia elétrica é uma das maiores preocupações da atualidade, pois é considerada essencial para o desenvolvimento da vida moderna. No Brasil, o suprimento dessa energia provém de um sistema hidrotérmico em que as usinas hidrelétricas fornecem cerca de $80 \%$ de energia enquanto o restante é abastecido por usinas baseadas na queima de combustíveis fósseis (CASARO; MARTÍNS, 2010). Além dos danos ambientais irrefutáveis inerentes a esse sistema e da dificuldade no suprimento da demanda energética, o crescente valor da tarifa de energia preocupa a sociedade como um todo (VICHI; MANSOR, 2009). Destaca-se, ainda, a crise financeira no setor público brasileiro que força a racionalização de recursos em diversas organizações públicas.

O Exército Brasileiro ciente de sua responsabilidade junto à sociedade, no que concerne ao emprego das verbas públicas e ao zelo pelas reservas naturais da nação, vem adotando medidas para a utilização eficiente de recursos energéticos. Entre as ações adotadas destaca-se a Política de Gestão Ambiental do Exército Brasileiro (PGAEB), aprovada pela Portaria n. 1138, de 22 de novembro de 2010 a qual visa procedimentos operacionais, educativos, logísticos, técnicos e administrativo para o gerenciamento ambiental sustentável. Um dos princípios apresentados nessa Política é a conservação do meio ambiente, por intermédio de incentivo ao estudo e à pesquisa de tecnologia para o uso de fontes alternativas.

Desse modo, as energias renováveis ganham destaque em meio à preocupação governamental com segurança energética e o crescimento econômico, já que são possibilidades para o poder público de melhorar sua imagem social e adequar-se às novas legislações, gerando economia efetiva nos recursos empregados, sejam esses recursos econômicos ou naturais (HOUGTON; JENKINS; EPHRAUMS, 1990). O crescimento da participação de fontes renováveis na matriz elétrica brasileira está estimado em 83,8\% até 2023 (SILVA, 2015). Nesse cenário sobressai a energia solar por ser limpa e infinitamente disponível podendo ser diretamente convertida em energia elétrica através de módulos fotovoltaicos (PATERNIANI et. al., 2005).

Diferentemente do sistema hidrotérmico, o sistema solar fotovoltaico tem baixo impacto ambiental, é livre de poluentes e pode ser utilizado ilimitadamente (ABINEE, 2012). No Brasil esse potencial é consideravelmente maior que a demanda, podendo suprir mais de duas vezes o consumo residencial. Apesar da abundância e dos benefícios ambientais o sistema fotovoltaico é pouco desenvolvido no país principalmente devido ao alto custo com investimento inicial o que inviabiliza sua expansão em larga escala (ABROMOVAY, 2010).

Isso posto, o presente estudo se propõe a verificar a viabilidade econômica de um sistema fotovoltaico nas Organizações Militares (OM's) de Santa Maria - RS, bem como, examinar os benefícios em termos financeiros e ambientais advindos da instalação. Especificamente, 
levantar-se-á os gastos com energia elétrica nas OM's, quantificar-se-á os custos de implantação e o tempo de retorno do investimento. Ademais, avaliar-se-á a economia de energia elétrica bem como a redução de poluentes após a implantação do projeto. Espera-se que a utilização de energia solar através da instalação de projetos fotovoltaicos represente uma alternativa de fonte renovável para energia elétrica, proporcionando uma redução de poluentes expelidos para atmosfera e uma economia de recursos financeiros para a organização.

O estudo se justifica haja vista a preocupação com a eficiência energética tal como a redução do consumo altamente dependente de recursos hídricos e combustíveis fósseis (DOS SANTOS et. al., 2015). Soma-se a isso a responsabilidade do Exército Brasileiro com a gestão ambiental e sustentabilidade da instituição, além do fato da cidade de Santa Maria comportar o segundo maior contingente militar do Brasil, de modo que ações desenvolvidas nessa localidade podem ter grande impacto em nível nacional. Com isso, os resultados tornam-se importantes indicadores na orientação de políticas públicas que visem a promoção do desenvolvimento da matriz energética do país de forma limpa, sem degradar o meio ambiente.

Além desta introdução o trabalho se estrutura em mais quatro seções, a segunda trata da sustentabilidade energética e uso de fontes alternativas esclarecendo acerca do emprego de energia solar e suas instalações, na terceira seção são explanados os métodos pelos quais se busca atingir os objetivos propostos, seguidamente são apresentados e discutidos os resultados, por fim tem-se as considerações finais que reforçam a justificativa do estudo apresentando suas contribuições para a formulação de políticas públicas bem como sugestões para agendas de pesquisa futura.

\section{SUSTENTABILIDADE, POLÍTICAS PÚBLICAS E ENERGIA SOLAR}

Diante da atual conjuntura dos problemas ambientais globais que vem gerando mudanças climáticas preocupantes, remete-se à necessidade de decisões sérias no tocante à mudanças de comportamento e tomada de ações sustentáveis, diárias e futuras. O uso desordenado do petróleo e do carvão deixa em alerta as Organizações Não Governamentais (ONGs) fazendo com que as mesmas, além de tomar medidas próprias de preservação, vão além de responsabilizar o poder privado, representado pelas empresas, estendendo a culpa e incumbindo a responsabilidade também ao poder público, visto que a ele cabe a regulamentação de ações voltadas a sustentabilidade.

Conforme o Instituto Brasileiro de Petróleo, Gás e Biocombustíveis (2016) o Brasil obteve destaque quando comparado aos demais países da América Latina em se tratando do aumento produtivo de petróleo, esse aumento é reflexo da crescente exploração impulsionada por novas tecnologias. Entretanto, os altos níveis de poluentes expelidos na atmosfera em decorrência da queima de combustíveis fósseis, mostram que o petróleo não é a melhor opção para a obtenção de energia. Assim, 
por ser um recurso finito e demasiadamente poluente, sua utilização intensiva na matriz energética brasileira precisa ser repensada, dando lugar a geração de energia renovável cujo potencial nacional é ocioso apesar de abundante.

Segundo relatórios do Greenpeace (2012) estima-se que o Brasil possa produzir até $143 \mathrm{GW}$ de energia eólica, considerando torres de 50 metros de altura, hoje, entretanto, já são utilizadas torres de 100 metros e, embora não existam números oficiais para este modelo, tudo indica que o valor ultrapassa $300 \mathrm{GW}$. O potencial energético proveniente das ondas e das marés está previsto em $114 \mathrm{GW}$, distribuído em todo o litoral brasileiro, em números equivale a toda energia produzida atualmente pelo Brasil. Já a energia advinda da biomassa tem um potencial auferido em cerca de 13,5 GW distribuído por todo território do país. Juntos, o potencial de energia eólica, biomassa, marés e ondas é cinco vezes maior do que as necessidades atuais, demostrando totais condições de cobrir, de forma limpa, as necessidades energéticas presentes e futuras. Enquanto isso, a intensidade da energia solar no Brasil é tanta, que uma área de 400 quilômetros quadrados, o que quase equivale ao Estado de Curitiba, geraria energia suficiente para suprir a demanda atual de eletricidade do país.

Umas das formas de aproveitar o potencial de energia solar é através da instalação de projetos fotovoltaicos. As instalações para captura de energia solar são compostas por painéis ou placas fotovoltaicas, um regulador de tensão, um sistema de armazenamento e por um inversor (ROSA, 2007). Esses painéis são conectados aos inversores solares, que por sua vez são ligados diretamente na rede elétrica (On Grid/Grid Tie), sustentados por suportes de alumínio com parafusos de aço inoxidável fixados no telhado das instalações. As estruturas de fixação estão dimensionadas para resistir à rajadas de vento, com velocidade de até $180 \mathrm{~km} / \mathrm{h}$. Os módulos fotovoltaicos (painéis) são instalados pelas empresas com uma vida útil estimada de mais de 25 anos e depreciação de o,8 \% ao ano.

Os painéis são formados por células fotovoltaicas construídas a partir de semicondutores, que, após receberem a luz solar em sua superfície, produzem tensão elétrica em seus terminais, realizando, portanto, função semelhante a um gerador, já que convertem corrente contínua em alternada (ESPOSITO; FUCHS, 2013). O projeto compreende também o sistema de conversão, que engloba um conjunto de conversores estáticos (inversores) os quais utilizam um sistema idôneo de transferência de potência à rede de distribuição, em conformidade aos requisitos técnicos e normas de segurança. $\mathrm{O}$ equipamento do inversor apresenta internamente todos os dispositivos necessários para uma conexão segura do sistema fotovoltaico com a rede elétrica. O papel principal do inversor solar no sistema fotovoltaico é inverter a energia elétrica gerada pelos painéis, de corrente continua para corrente alternada (CC/CA), conforme requer a rede elétrica comercial. O Seu papel secundário é garantir a segurança do sistema e medir a energia pro- 
duzida pelos painéis solares. Para completar o sistema são utilizados baterias, cabos condutores isolados, cabeamento elétrico especial em cobre para corrente contínua e conectores especiais. A Figura 1 ilustra a instalação de um sistema fotovoltaico.

FIGURA 1 - Funcionamento básico de um sistema fotovoltaico

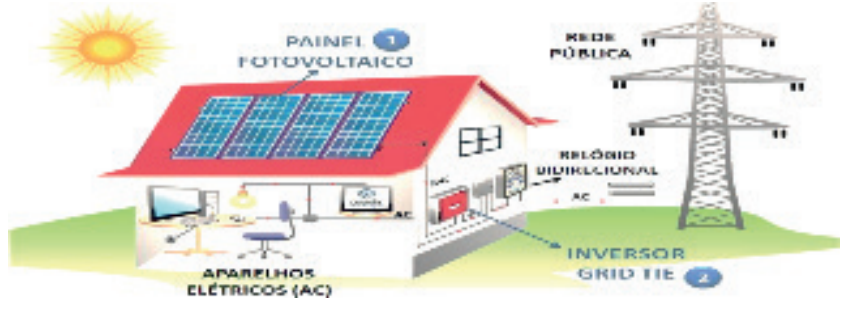

FONTE: (SOLARIS, 2015).

Enquanto o painel solar fotovoltaico produz energia elétrica em corrente contínua (CC) o inversor solar inverte a corrente em alternada (CA) e equaliza com a rede elétrica. Desta forma, a energia gerada pelo painel solar fica idêntica à energia que se consome da rede elétrica. Após sair do inversor solar o próximo destino é o quadro de luz de onde ela é distribuída podendo ser utilizada para o consumo residencial, comercial ou industrial (SOLARIS, 2015). Depois de alimentar utensílios, eletrodomésticos, equipamentos e máquinas, o excesso retorna para a rede elétrica através do relógio de luz fazendo com que este "rode ao contrário", e gere um crédito de energia para ser utilizado nos momentos em que não há produção, como por exemplo à noite ou meses em que a intensidade luminosa do sol é mais baixa.

Em outras palavras, além da produção renovável de energia, a instalação auxilia na economia de luz elétrica reduzindo inclusive o valor da fatura (SOLARIS, 2015). Como incentivo ao consumidor, tanto para o uso da energia solar na iniciativa privada quanto nas organizações governamentais, a Agência Nacional de Energia Elétrica estabeleceu através da Resolução Normativa n. 482, de 17/07/2012, a possibilidade de gerar energia elétrica a partir da energia solar em estabelecimentos. Tal possibilidade abrange inclusive a microgeração e minigeração de distribuição de energia elétrica, como também o sistema de compensação (ANEEL, 2012). Assim, a partir da assinatura dessa resolução, pode-se instalar um projeto de energia solar tanto para ter economia na conta de luz, quanto para compensar o potencial energético gerado com o utilizado das concessionárias do serviço público de energia elétrica, permitindo a troca da energia produzida pelos painéis por créditos em quilowatt-hora $(\mathrm{kWh})$ na fatura, o que resulta em menos recursos e corte gastos.

\section{METODOLOGIA}

O estudo faz uso de uma pesquisa exploratória que de acordo com Gil (2002) proporciona maior familiaridade com o problema, assumindo a forma de pesquisa bibliográfica ou de estudo de caso. 
Segundo Yin (2005) o Estudo de Caso é utilizado principalmente para investigar um fenômeno num contexto real onde o limite entre eles não pode ser claramente definido, sendo seu objetivo o aprofundamento dos aspectos característicos do fenômeno. No que se refere a coleta e análise, o estudo caracteriza-se como quantitativo. Para o levantamento das informações procedeu-se uma pesquisa documental. Marconi e Lakatos (2011) explicam que tal pesquisa se baseia em documentos, escritos ou não, tais como arquivos públicos, arquivos privados e fontes estatísticas.

Os dados coletados são provenientes de fontes secundárias sendo os gastos com energia elétrica obtidos diretamente nas OM's, através do levantamento das contas de energia elétrica de doze meses, período compreendido entre agosto do ano 2015 e julho de 2016. Optou-se por estudar as Organizações Militares de Santa Maria - RS, em virtude de o município concentrar o segundo maior contingente militar do Brasil. Para quantificar os custos de investimento do projeto fotovoltaico primeiramente foram analisados os gastos com energia elétrica de todas as OM's da cidade, a partir desse levantamento adotou-se como critério amostral a seleção da OM's de maior consumo, de consumo intermediário e a de menor consumo, identificadas respectivamente como Projeto 1, Projeto 2 e Projeto 3.

Segundo Hirschfeld (2009), para que haja viabilidade econômica os benefícios gerados pelo investimento devem superar os custos aplicados, dessa forma, para verificar a viabilidade econômica da instalação dos projetos fotovoltaicos, primeiramente procedeu-se uma pesquisa de mercado com empresas especializadas na instalação de projetos de energia solar no intuito de obter informações acerca dos custo de investimento. Para essa etapa, levou-se em consideração o potencial de radiação, a inclinação e a posição dos painéis, características estas, fundamentais já que o mal dimensionamento implica perdas de absorção energética. Na sequência, levantou-se o valor mensal de economia de energia elétrica que cada Projeto obteria na fatura, esses valores são utilizados como parâmetro mensal de fluxo de caixa nos cálculos que investigam o retorno do investimento.

Entre os métodos que mensuram o tempo de recuperação do capital aplicado destaca-se a aplicação de payback descontado que difere do payback simples por considerar o valor do dinheiro no tempo através da inserção de uma taxa de desconto que é determinada pelo próprio investidor como parâmetro para remuneração de seu capital. O cálculo do payback descontado é dado pela Equação 1 e geralmente complementado por outros indicadores como o valor presente líquido (VPL) e a taxa interna de retorno (TIR). O VPL, conforme Souza (2003, p. 74), corresponde "à diferença entre o valor presente das entradas líquidas de caixa associadas ao projeto e o investimento inicial necessário", já a TIR representa a rentabilidade do projeto expressa em termos de taxa de juros. (ASSAF NETO, 2003). 


$$
\begin{aligned}
& V_{P L}=\sum_{n=1}^{n=N} \frac{F C_{t}}{(1+i)^{n}} \\
& \text { Onde: } \\
& \text { VPL: Valor Presente Líquido; } \\
& \text { Fc: fluxo de caixa; } \\
& \text { t: momento em que o fluxo de caixa ocorreu; } \\
& \text { i: taxa de desconto (ou taxa mínima de atratividade); } \\
& \text { n: período de tempo. }
\end{aligned}
$$

Para este cálculo tomou-se 25 anos como parâmetro para o tempo de retorno do investimento o que corresponde a vida útil de uma instalação fotovoltaica e para taxa requerida, utilizada como taxa mínima de atratividade (TMA) tomou-se como base o percentual de $7,4 \%$ ao ano, definido definida a partir da Taxa Selic. A análise se completa com as projeções para redução dos níveis de gases de efeito cujos dados formam fornecidos pela empresa especializada na instalação de projeto de energia solar.

\section{RESULTADOS E DISCUSSÕES}

A partir da pesquisa documental, realizada diretamente nas organizações militares escolhidas, foram levantados os gastos históricos de energia solar, entre os meses de agosto de 2015 a julho de 2016, das dezoito Guarnições de Santa Maria. O levantamento dos dados deu-se através das faturas. A cobrança de energia elétrica é feita de acordo com o sistema de bandeiras tarifárias vigentes, formato regulamentado sob a Resolução Normativa n⿳o .547/13 pela ANEEL (Agência Nacional de Energia Elétrica), desde o ano de 2015. As bandeiras tarifárias têm como objetivo repassar para o consumidor o aumento dos custos de forma transparente.

Quando a bandeira está verde significa que as circunstâncias são favoráveis para a geração de energia mantendo o valor da tarifa elétrica estacionado. Já quando se encontra amarela, o momento não é tão favorável acarretando o aumento de um centavo e meio por quilowatt-hora. Em se tratando de bandeira vermelha as condições para produção de energia são inadequadas e o aumento nos custos passa a ser de três centavos por quilowatt-hora quando esta está em patamar 1 e pouco mais de quatro centavos quando está em patamar 2. O Quadro 1 ilustra o sistema de tarifas de energia elétrica de acordo com as bandeiras:

QUADRO 1 - Bandeiras tarifárias (Sistema de bandeiras tarifárias)

\begin{tabular}{|c|c|c|}
\hline Bandeira & $\begin{array}{c}\text { Condições para geração de } \\
\text { energia }\end{array}$ & Custo \\
\hline Verde & Favorável & $\begin{array}{c}\text { Não há acréscimo na } \\
\text { tarifa }\end{array}$ \\
\hline Amarela & Menos favorável & $\begin{array}{c}\text { Acréscimo de } \mathrm{R} \$ 0,015 \\
\text { para cada } 1 \mathrm{kWh}\end{array}$ \\
\hline Vermelha - Patamar 1 & Custosas & $\begin{array}{c}\text { Acréscimo de } \mathrm{R} \$ 0,030 \\
\text { para cada } 1 \mathrm{kWh}\end{array}$ \\
\hline Vermelha - Patamar 2 & Mais custosas & $\begin{array}{c}\text { Acréscimo de } \mathrm{R} \$ 0,045 \\
\text { para cada } 1 \mathrm{kWh}\end{array}$ \\
\hline
\end{tabular}


A seguir são demonstrados os gastos de energia elétrica em quilowatt hora (kWh), o valor (R\$) pago mensalmente por fatura e a bandeira tarifária vigente no período, assim como o total anual do consumo e o valor pago em Reais (R $\$$ ), de 18 OM's, as quais foram designadas de OM 1 até OM 18. O Quadro 2 mostra os dados das 18 Organizações Militares.

QUADRO 2 - Gasto energético da OM 1 à OM 18

\begin{tabular}{|c|c|c|c|c|c|c|c|}
\hline \multirow[t]{2}{*}{ Ano } & $\begin{array}{c}\text { Consumo } \\
\text { kWh }\end{array}$ & $\begin{array}{l}\text { Valor } \\
\text { Fatura } \\
\text { (R\$) }\end{array}$ & $\begin{array}{c}\text { Consumo } \\
\text { kWh }\end{array}$ & $\begin{array}{c}\text { Valor } \\
\text { Fatura (R\$) }\end{array}$ & $\begin{array}{c}\text { Consumo } \\
\text { kWh }\end{array}$ & $\begin{array}{c}\text { Valor } \\
\text { Fatura (R\$) }\end{array}$ & \multirow[t]{2}{*}{$\begin{array}{l}\text { Bandera } \\
\text { tarifária }\end{array}$} \\
\hline & \multicolumn{2}{|c|}{ OM 1} & \multicolumn{2}{|c|}{ OM 2} & \multicolumn{2}{|c|}{ OM 3} & \\
\hline $8 / 2015$ & 21140 & $15.013,50$ & 18828 & $15.131,49$ & 34810 & $29.942,24$ & Vermelha \\
\hline $9 / 2015$ & 19320 & $14.039,36$ & 20151 & $16.974,17$ & 26723 & $22.025,63$ & Vermelha \\
\hline $10 / 2015$ & 19460 & $14.565,63$ & 17229 & $13.337,60$ & 26723 & $22.477,07$ & Vermelha \\
\hline $11 / 2015$ & 18480 & $14.263,65$ & 19972 & $14.508,73$ & 27793 & $23.028,84$ & Vermelha \\
\hline $12 / 2015$ & 16100 & $12.179,22$ & 21304 & $14.120,93$ & 26404 & $20.288,48$ & Vermelha \\
\hline $1 / 2016$ & 17080 & $8.664,35$ & 23415 & $11.322,98$ & 30341 & $25.158,09$ & Vermelha \\
\hline $2 / 2016$ & 20580 & $10.195,02$ & 27805 & $14.703,07$ & 36434 & $28.993,74$ & Vermelha \\
\hline $3 / 2016$ & 18200 & $11.005,18$ & 26248 & $14.065,84$ & 50182 & $41.278,28$ & Amarela \\
\hline $4 / 2016$ & 18340 & $12.093,72$ & 26065 & $18.505,21$ & 37084 & $34.940,23$ & Verde \\
\hline $5 / 2016$ & 20860 & $15.425,30$ & 22167 & $17.503,16$ & 38478 & $31.184,53$ & Verde \\
\hline $6 / 2016$ & 19740 & $14.064,14$ & 21171 & $16.279,60$ & 28840 & $21.064,17$ & Verde \\
\hline $7 / 2016$ & 20440 & $15.368,29$ & 24835 & $20.461,85$ & 28297 & $25.895,27$ & Verde \\
\hline TOTAL & 229740 & $156.877,36$ & 269190 & $186.914,63$ & 455346 & $304.229,77$ & \\
\hline \multirow[t]{2}{*}{ MÉDIA } & 19145 & $13.073,11$ & 22432,5 & $15.576,22$ & 37945,5 & $25.352,48$ & \\
\hline & \multicolumn{2}{|c|}{ OM 4} & \multicolumn{2}{|c|}{ OM 5} & \multicolumn{2}{|c|}{ OM 6} & \\
\hline $8 / 2015$ & 10460 & $7.454,24$ & 42640 & $32.017,95$ & 45149 & $34.899,76$ & Vermelha \\
\hline $9 / 2015$ & 11100 & $8.133,80$ & 35711 & $23.150,57$ & 30451 & $24.344,21$ & Vermelha \\
\hline $10 / 2015$ & 9660 & $6.958,21$ & 32267 & $23.191,40$ & 33902 & $27.024,52$ & Vermelha \\
\hline $11 / 2015$ & 10640 & $7.852,02$ & 33661 & $22.928,04$ & 31968 & $25.539,48$ & Vermelha \\
\hline $12 / 2015$ & 11350 & $8.200,07$ & 33333 & $21.495,82$ & 34080 & $24.717,66$ & Vermelha \\
\hline $1 / 2016$ & 13440 & $4.758,25$ & 37802 & $22.476,89$ & 37666 & $29.305,89$ & Vermelha \\
\hline $2 / 2016$ & 12060 & $6.366,15$ & 38294 & $27.551,60$ & 39173 & $30.747,83$ & Vermelha \\
\hline $3 / 2016$ & 12980 & $7.322,62$ & 39565 & $27.909,06$ & 45518 & $33.996,84$ & Amarela \\
\hline $4 / 2016$ & 11740 & $7.798,92$ & 38294 & $25.873,94$ & 37421 & $31.974,64$ & Verde \\
\hline $5 / 2016$ & 9280 & $6.899,11$ & 41082 & $25.903,54$ & 39322 & $29.621,90$ & Verde \\
\hline $6 / 2016$ & 9160 & $6.750,61$ & 39319 & $24.755,31$ & 35726 & $26.072,69$ & Verde \\
\hline $7 / 2016$ & 11260 & $8.341,67$ & 43378 & $26.975,65$ & 42192 & $31.767,94$ & Verde \\
\hline TOTAL & 133130 & $86.835,67$ & 392109 & $326.276,57$ & 452568 & $350.013,36$ & \\
\hline \multirow[t]{2}{*}{ MÉDIA } & 11094,166 & $7.236,31$ & 32675,75 & $27.189,71$ & 37714 & $29.167,78$ & \\
\hline & \multicolumn{2}{|c|}{ OM 7} & \multicolumn{2}{|c|}{ OM 8} & \multicolumn{2}{|c|}{ OM 9} & \\
\hline $8 / 2015$ & 22847 & $16.623,24$ & 41400 & $27.229,83$ & 32400 & $25.893,03$ & Vermelha \\
\hline $9 / 2015$ & 20172 & $15.001,41$ & 37800 & $25.655,18$ & 30240 & $22.487,03$ & Vermelha \\
\hline
\end{tabular}


Revista de Gestão Pública

PRÁTICAS E DESAFIOS

ISSN: 2177-1243

\begin{tabular}{|c|c|c|c|c|c|c|c|}
\hline $10 / 2015$ & 21064 & $14.972,09$ & 35400 & $23.874,96$ & 26880 & $21.252,15$ & Vermelha \\
\hline $11 / 2015$ & 23063 & $16.459,34$ & 33960 & $23.757,99$ & 29280 & $21.646,28$ & Vermelha \\
\hline $12 / 2015$ & 22694 & $16.275,61$ & 33120 & $22.846,23$ & 27840 & $18.326,63$ & Vermelha \\
\hline $1 / 2016$ & 29059 & $20.536,74$ & 38880 & $27.021,06$ & 33600 & $23.631,76$ & Vermelha \\
\hline $2 / 2016$ & 28567 & $20.245,30$ & 40320 & $28.394,07$ & 30720 & $26.452,00$ & Vermelha \\
\hline $3 / 2016$ & 26906 & $24.242,17$ & 43080 & $36.589,38$ & 34320 & $30.772,54$ & Amarela \\
\hline $4 / 2016$ & 24692 & $17.629,98$ & 41760 & $27.341,92$ & 35040 & $27.532,79$ & Verde \\
\hline $5 / 2016$ & 20295 & $15.865,98$ & 42120 & $27.659,39$ & 39360 & $26.964,36$ & Verde \\
\hline $6 / 2016$ & 22079 & $14.160,50$ & 33480 & $22.647,45$ & 33120 & $23.858,53$ & Verde \\
\hline $7 / 2016$ & 23985 & $17.735,90$ & 39600 & $26.315,26$ & 31440 & $26.714,10$ & Verde \\
\hline TOTAL & 285423 & $209.748,26$ & 460920 & $319.332,72$ & 384240 & $295.531,20$ & \\
\hline MÉDIA & 23785,25 & $17.479,02$ & 38410 & $26.611,06$ & 32020 & $24.627,60$ & \\
\hline & \multicolumn{2}{|c|}{ OM 10} & \multicolumn{2}{|c|}{ OM 11} & \multicolumn{2}{|c|}{ OM 12} & \\
\hline $8 / 2015$ & 44496 & $31.950,06$ & 36431 & $19.141,04$ & 25920 & $19.193,42$ & Vermelha \\
\hline $9 / 2015$ & 36313 & $26.174,95$ & 22761 & $16.557,47$ & 24000 & $19.747,19$ & Vermelha \\
\hline $10 / 2015$ & 38589 & $26.999,63$ & 22761 & $17.396,77$ & 24000 & $17.706,33$ & Vermelha \\
\hline $11 / 2015$ & 39275 & $28.176,93$ & 15590 & $17.025,78$ & 20160 & $15.704,62$ & Vermelha \\
\hline $12 / 2015$ & 42591 & $32.801,02$ & 24204 & $17.972,14$ & 21120 & $16.371,93$ & Vermelha \\
\hline $1 / 2016$ & 55507 & $41.673,50$ & 25636 & $18.725,08$ & 27840 & $20.671,99$ & Vermelha \\
\hline $2 / 2016$ & 65019 & $50.947,67$ & 43773 & $20.359,44$ & 32160 & $23.104,70$ & Vermelha \\
\hline $3 / 2016$ & 57146 & $47.612,19$ & 42494 & $15.990,17$ & 29760 & $21.535,20$ & Amarela \\
\hline $4 / 2016$ & 54589 & $37.330,43$ & 30278 & $17.546,68$ & 27360 & $21.641,01$ & Verde \\
\hline $5 / 2016$ & 40155 & $30.166,36$ & 29232 & $17.364,58$ & 24480 & $17.890,52$ & Verde \\
\hline $6 / 2016$ & 40864 & $27.979,56$ & 23029 & $16.301,76$ & 20640 & $15.827,96$ & Verde \\
\hline $7 / 2016$ & 47280 & $39.530,46$ & 24259 & $18.126,38$ & 24960 & $18.121,36$ & Verde \\
\hline TOTAL & 561824 & $421.342,76$ & 340448 & $212.507,29$ & 302400 & $227.516,23$ & \\
\hline \multirow[t]{2}{*}{ MÉDIA } & 46818,67 & $35.111,90$ & 28370,67 & $17.708,94$ & 25200 & $18.959,69$ & \\
\hline & \multicolumn{2}{|c|}{ OM 13} & \multicolumn{2}{|c|}{ OM 14} & \multicolumn{2}{|c|}{ OM 15} & \\
\hline $8 / 2015$ & 42426 & $32.278,92$ & 25984 & $18.324,82$ & 9525 & $7.513,07$ & Vermelha \\
\hline $9 / 2015$ & 52013 & $36.760,61$ & 22632 & $16.539,19$ & 8440 & $6.824,23$ & Vermelha \\
\hline $10 / 2015$ & 45584 & $34.596,64$ & 21863 & $15.218,98$ & 8497 & $6.658,57$ & Vermelha \\
\hline $11 / 2015$ & 51604 & $38.093,66$ & 32503 & $18.992,59$ & 7924 & $6.171,69$ & Vermelha \\
\hline $12 / 2015$ & 45438 & $34.794,06$ & 24139 & $16.651,02$ & 7759 & $6.340,80$ & Vermelha \\
\hline $1 / 2016$ & 48989 & $40.830,99$ & 27245 & $12.229,22$ & 3413 & $2.426,80$ & Vermelha \\
\hline $2 / 2016$ & 45080 & $34.499,57$ & 36808 & $19.595,27$ & 5737 & $4.080,50$ & Vermelha \\
\hline $3 / 2016$ & 45914 & $35.335,45$ & 24863 & $19.814,22$ & 13627 & $8.746,70$ & Amarela \\
\hline $4 / 2016$ & 43658 & $34.970,55$ & 28721 & $19.192,43$ & 14269 & $7.515,64$ & Verde \\
\hline $5 / 2016$ & 48927 & $38.524,51$ & 22448 & $15.168,84$ & 9741 & $7.886,62$ & Verde \\
\hline $6 / 2016$ & 53357 & $40.935,68$ & 24077 & $18.913,48$ & 8944 & $7.034,15$ & Verde \\
\hline $7 / 2016$ & 55821 & $42.293,37$ & 22171 & $17.254,64$ & 10388 & $8.856,21$ & Verde \\
\hline TOTAL & 578811 & $443.914,01$ & 313454 & $207.894,70$ & 108264 & $80.054,98$ & \\
\hline MÉDIA & 48234,25 & $36.992,83$ & 26121,16 & $17.324,56$ & 9022 & $6.671,25$ & \\
\hline
\end{tabular}




\begin{tabular}{|c|c|c|c|c|c|c|c|}
\hline & \multicolumn{2}{|c|}{ OM 16 } & \multicolumn{2}{c|}{ OM 17 } & \multicolumn{2}{c|}{ OM 18 } & \\
\hline $8 / 2015$ & 24870 & $22.957,98$ & 14145 & $11.059,96$ & 409 & $1.064,43$ & Vermelha \\
\hline $9 / 2015$ & 23044 & $22.384,61$ & 13325 & $10.830,82$ & 393 & $1.070,43$ & Vermelha \\
\hline $10 / 2015$ & 22971 & $21.680,33$ & 13179 & $10.560,23$ & 186 & $1.050,64$ & Vermelha \\
\hline $11 / 2015$ & 28610 & $24.799,35$ & 14878 & $11.829,43$ & 250 & $1.044,02$ & Vermelha \\
\hline $12 / 2015$ & 26930 & $24.027,51$ & 14678 & $11.854,29$ & 296 & $1.024,04$ & Vermelha \\
\hline $1 / 2016$ & 33712 & $17.212,73$ & 17302 & $8.911,05$ & 338 & 845,38 & Vermelha \\
\hline $2 / 2016$ & 30643 & $15.542,90$ & 15744 & $9.225,00$ & 283 & 838,96 & Vermelha \\
\hline $3 / 2016$ & 25614 & $13.661,72$ & 22058 & $10.772,57$ & 293 & 872,60 & Amarela \\
\hline $4 / 2016$ & 24786 & $20.511,86$ & 16630 & $10.924,90$ & 372 & 962,00 & Verde \\
\hline $5 / 2016$ & 23425 & $21.907,40$ & 14140 & $10.022,22$ & 355 & $1.381,26$ & Verde \\
\hline $6 / 2016$ & 24321 & $22.298,24$ & 11354 & $8.116,09$ & 357 & $1.066,98$ & Verde \\
\hline $7 / 2016$ & 24130 & $25.077,01$ & 18296 & $15.215,84$ & 381 & $1.396,04$ & Verde \\
\hline TOTAL & 313056 & $252.061,64$ & 185729 & $129.322,40$ & 3913 & $12.616,78$ & \\
\hline MÉDIA & 26088 & $21.005,14$ & 15477,41 & $10.776,87$ & 326,08 & $1.051,40$ & \\
\hline
\end{tabular}

FONTE: Fonte: Elaborado pelos autores, 2018.

A partir dos quadros apresentados verifica-se que nos meses de julho e agosto houveram grandes gastos energéticos nas OM's, a justificativa para isto é a temperatura ambiental que nesta época do ano é mais baixa, o que leva a uma maior utilização dos chuveiros elétricos, principais responsáveis pelo alto índice de consumo de energia elétrica. Estes são utilizados com temperaturas mais altas, principalmente após as atividades físicas dos militares, conhecidas como Treinamento Físico Militar (TFM). Também, nestes meses, o efetivo de pessoal está completo por se tratar do meio do corrente ano de instrução, ou seja, 100\% do efetivo profissional e dos soldados que estão cumprindo o serviço militar obrigatório estão em serviço nas OM's.

Seguindo a análise, percebe-se que há uma diminuição dos gastos nos meses de setembro e outubro justificada pelo início da primavera, estação do ano, que no Rio Grande do Sul, as temperaturas começam a se elevar. Verifica-se também valores mais baixos pagos nas faturas de novembro e de dezembro. Cabe ressaltar que a partir destes meses, normalmente, o Exército Brasileiro entra no regime de meio expediente (horário reduzido), isto ocorre com o objetivo de economia em alimentação e principalmente em energia elétrica.

O mês de janeiro, juntamente com novembro e dezembro mostram, mesmo com o maior uso de aparelhos de refrigeração, os menores gastos energéticos nas OM's, pois além de estar em meio expediente, o efetivo que está cumprindo seu ano obrigatório é licenciado no início deste mês, ficando apenas 50\% do incorporado no ano interior, diminuindo por volta de $25 \%$ do efetivo total do aquartelamento. No mês de fevereiro percebe-se um aumento considerável no gasto mensal de kWh, em algumas OM's nesse mês é registrado o maior pico de consumo energético. 
Em março, semelhante a julho e agosto, como no início da análise, há grande gasto energético. Isso acontece em função do retorno do efetivo para o começo de um novo ano de instrução ocorrendo a incorporação de uma nova turma de soldados no serviço militar obrigatório. Por conseguinte, a Tabela $\mathrm{I}$ apresenta o consumo total anual em $\mathrm{kWh}$, o valor total anual pago em reais, a média mensal dos 12 meses em $\mathrm{kWh}$ e o valor médio pago dentro do mês (no período de doze meses) em cada uma das 18 Organizações Militares de Santa Maria.

TABELA 1 - Gasto energético anual e média mensal das 18 Organizações Militares

\begin{tabular}{|c|c|c|c|c|}
\hline \multirow{2}{*}{$\begin{array}{c}\text { Organização } \\
\text { Militar }\end{array}$} & \multicolumn{2}{|c|}{ Anual } & \multicolumn{2}{c|}{ Mensal (12 meses) } \\
\cline { 2 - 5 } & kWh total & Valor total & Média kWh & Valor médio \\
\hline OM 1 & 229740 & $\mathrm{R} \$ 156.877,36$ & 19145 & $\mathrm{R} \$ 13.073,11$ \\
\hline OM 2 & 269190 & $\mathrm{R} \$ 186.914,63$ & 22432,5 & $\mathrm{R} \$ 15.576,22$ \\
\hline OM 3 & 455346 & $\mathrm{R} \$ 304.229,77$ & 37945,5 & $\mathrm{R} \$ 25.352,48$ \\
\hline OM 4 & 133130 & $\mathrm{R} \$ 86.835,67$ & 11094,17 & $\mathrm{R} \$ 7.236,31$ \\
\hline OM 5 & 392109 & $\mathrm{R} \$ 326.276,57$ & 32675,75 & $\mathrm{R} \$ 27.189,71$ \\
\hline OM 6 & 452568 & $\mathrm{R} \$ 350.013,36$ & 37714 & $\mathrm{R} \$ 29.167,78$ \\
\hline OM 7 & 285423 & $\mathrm{R} \$ 209.748,26$ & 23785,25 & $\mathrm{R} \$ 17.479,02$ \\
\hline OM 8 & 460920 & $\mathrm{R} \$ 319.332,72$ & 38410 & $\mathrm{R} \$ 26.611,06$ \\
\hline OM 9 & 384240 & $\mathrm{R} \$ 295.531,20$ & 32020 & $\mathrm{R} \$ 24.627,60$ \\
\hline OM 10 & 561824 & $\mathrm{R} \$ 421.342,76$ & 46818,67 & $\mathrm{R} \$ 35.111,90$ \\
\hline OM 11 & 340448 & $\mathrm{R} \$ 212.507,29$ & 28370,67 & $\mathrm{R} \$ 17.708,94$ \\
\hline OM 12 & 302400 & $\mathrm{R} \$ 227.516,23$ & 25200 & $\mathrm{R} \$ 18.959,69$ \\
\hline OM 13 & 578811 & $\mathrm{R} \$ 443.914,01$ & 48234,25 & $\mathrm{R} \$ 36.992,83$ \\
\hline OM 14 & 313454 & $\mathrm{R} \$ 207.894,70$ & 26121,167 & $\mathrm{R} \$ 17.324,56$ \\
\hline OM 15 & 108264 & $\mathrm{R} \$ 80.054,98$ & 9022 & $\mathrm{R} \$ 6.671,25$ \\
\hline OM 16 & 313056 & $\mathrm{R} \$ 252.061,64$ & 26088 & $\mathrm{R} \$ 21.005,14$ \\
\hline OM 17 & 185729 & $\mathrm{R} \$ 129.322,40$ & 15477,42 & $\mathrm{R} \$ 10.776,87$ \\
\hline OM 18 & 3913 & $\mathrm{R} \$ 12.616,78$ & 326,08 & $\mathrm{R} \$ 1.051,40$ \\
\hline
\end{tabular}

FONTE: Fonte: Elaborado pelos autores.

Através da Tabela 1 percebe-se, uma grande variação no consumo de energia elétrica entre as OM's justificada pelas diferenças organizacionais da missão institucional (Operacional/ Saúde/Administrativa) e do efetivo de militares entre umas e outras. A apuração do valor médio mensal de gasto dentro de um ano, em kWh é importante para executar-se o cálculo da capacidade de geração de energia solar que o sistema irá precisar para suportar o gasto energético das instalações onde se quer implantar o sistema.

Diante dos resultados fornecidos pela Tabela 1 foram selecionadas três OM's, para a implantação de um projeto fotovoltaico, sendo elas a de maior consumo, de consumo intermediário e a de menor consumo, de modo que o consumo é aviado em termos de média mensal de $\mathrm{kWh}$. De acordo com esse critério as OM's selecionadas foram designadas respectivamente como Projetos 1, 2 e 3. A Tabela 2 representa tal seleção em ordem decrescente de gasto de energia elétrica evidenciando diretamente os três valores escolhidos para estudo dentro das dezoito OM's. 
TABELA 2 - Gasto energético anual e média mensal de 3 Organizações Militares

\begin{tabular}{|c|c|c|c|c|c|}
\hline \multirow{2}{*}{$\begin{array}{c}\text { Organização } \\
\text { Militar }\end{array}$} & Projeto & \multicolumn{2}{|c|}{ Anual } & \multicolumn{2}{c|}{ Mensal (12 meses) } \\
\cline { 2 - 6 } & & $\begin{array}{c}\text { kWh } \\
\text { total }\end{array}$ & Valor total & $\begin{array}{c}\text { Média } \\
\text { kWh }\end{array}$ & $\begin{array}{c}\text { Valor } \\
\text { médio }\end{array}$ \\
\hline OM 13 & 1 & 578811 & $\mathrm{R} \$ 443.914,01$ & 48234,25 & $\begin{array}{c}\mathrm{R} \$ \\
36.992,83\end{array}$ \\
\hline OM 1 & 2 & 229740 & $\mathrm{R} \$ 156.877,36$ & 19145,00 & $\begin{array}{c}\mathrm{R} \$ \\
13.073,11\end{array}$ \\
\hline OM 18 & 3 & 3913 & $\mathrm{R} \$ 12.616,78$ & 326,08 & $\begin{array}{c}\mathrm{R} \$ \\
1.051,40\end{array}$ \\
\hline
\end{tabular}

Feito isso, inicia-se a coleta de informações referente à montagem e instalação de um projeto fotovoltaico. Para tanto, formam consultadas empresas especializadas em montagem e manutenção de equipamentos coletores de energia solar de modo a obter um orçamento prévio da instalação. Através da pesquisa e solicitação de orçamento, foi direcionado pela empresa um sistema fotovoltaico que suprisse a demanda energética total das OM's, tendo sobra na geração em alguns momentos do ano, de modo que a tarifa da energia gerada pelo sistema fosse a mais vantajosa possível, podendo acumular bônus para meses futuros. A Tabela 3 descrimina todos os gastos envolvidos na a composição do sistema fotovoltaico para os três projetos.

TABELA 3 - Composição dos custos dos investimentos dos projetos 1, 2 e 3.

\begin{tabular}{|l|c|c|c|}
\hline \multirow{2}{*}{$\begin{array}{c}\text { Composição do Sistema } \\
\text { Fotovoltaico }\end{array}$} & \multicolumn{3}{c|}{ Quantidade } \\
\cline { 2 - 4 } & $\begin{array}{c}\text { Projeto 1 } \\
\text { OM13 }\end{array}$ & $\begin{array}{c}\text { Projeto 2 } \\
\text { OM 1 }\end{array}$ & $\begin{array}{c}\text { Projeto 3 } \\
\text { OM18 }\end{array}$ \\
\hline $\begin{array}{l}\text { Módulos (painéis) em silício - Marca } \\
\text { JINCO SOLAR }\end{array}$ & 1378 & 547 & 9 \\
\hline $\begin{array}{l}\text { Inversores (Conversor CC/AA) - } \\
\text { Fronius Eco - 27 kW }\end{array}$ & 15 & 6 & 1 \\
\hline $\begin{array}{l}\text { Estruturas de fixação (Suporte em } \\
\text { alumínio) }\end{array}$ & 1378 & 547 & 9 \\
\hline $\begin{array}{l}\text { Instalação completa do sistema } \\
\text { fotovoltaico }\end{array}$ & 1 & 1 & 1 \\
\hline \multicolumn{1}{|c|}{ Valor total (R\$) } & $1.890 .060,00$ & $753.300,00$ & $17.550,00$ \\
\hline
\end{tabular}

FONTE: Elaborado pelos autores a partir dos orçamentos fornecidos pela empresa de instalação de sistema fotovoltáico, 2018.

Em seguida, analisou-se a projeção da produção de energia dos três projetos, considerando a radiação solar na horizontal, de acordo com as características locacionais de cada OM's. O Projetor é sistema de produção de eletricidade através da conversão fotovoltaica, com uma potência de pico igual a 440,96 kWp com essa potência há uma produção de 580.137,2 kWh por ano, distribuídos em uma área de 2.673,32 $\mathrm{m}^{2}$. O Projeto 2 é construído com uma potência de pico igual a 175,04 kWp, obtendo-se uma produção de $230.286,7 \mathrm{kWh}$ por ano, distribuídos em uma área de 1.061,18 m². Já o Projeto 3, de menor potência de pico, chega a 2,88 kWp para uma produção de $4.125,8 \mathrm{kWh}$ por ano, distribuídos em uma área de $17,46 \mathrm{~m}^{2}$. Assim, a partir destes dados foi possível construir a projeção mensal de produção de energia fotovotáica para cada projeto (Tabela 4) 
TABela 4 - Projeção da Produção de energia solar para os Projetos 1, 2 e 3

\begin{tabular}{|c|c|c|c|c|c|c|}
\hline \multirow[b]{2}{*}{ Mês } & \multicolumn{2}{|c|}{$\begin{array}{l}\text { Projeto 1- } \\
\text { OM } 13\end{array}$} & \multicolumn{2}{|c|}{$\begin{array}{l}\text { Projeto } 2 \text { - } \\
\text { OM } 1\end{array}$} & \multicolumn{2}{|c|}{$\begin{array}{l}\text { Projeto } \\
\text { 3- OM 18 }\end{array}$} \\
\hline & $\begin{array}{c}\text { Total } \\
\text { diário } \\
\text { [kWh] }\end{array}$ & $\begin{array}{l}\text { Total } \\
\text { mensal } \\
\text { [kWh] }\end{array}$ & $\begin{array}{c}\text { Total } \\
\text { diário } \\
\text { [kWh] }\end{array}$ & $\begin{array}{c}\text { Total } \\
\text { mensal } \\
{[\mathrm{kWh}]}\end{array}$ & $\begin{array}{l}\text { Total } \\
\text { diário } \\
\text { [kWh] }\end{array}$ & $\begin{array}{c}\text { Total } \\
\text { mensal } \\
{[\mathrm{kWh}]}\end{array}$ \\
\hline Janeiro & 1940,340 & 60150,526 & 770,222 & 23876,878 & 13,799 & 427,776 \\
\hline Fevereiro & 1813,193 & 50769,411 & 719,751 & 20153,024 & 12,895 & 361,060 \\
\hline Março & 1700,936 & 52729,002 & 675,190 & 20930,888 & 12,097 & 374,996 \\
\hline Abril & 1388,261 & 41647,830 & 551,073 & 16532,194 & 9,873 & 296,189 \\
\hline Maio & 1321,377 & 40962,691 & 524,523 & 16260,226 & 9,397 & 291,317 \\
\hline Junho & 1112,815 & 33384,448 & 441,734 & 13252,027 & 7,914 & 237,422 \\
\hline Julho & 1195,588 & 37063,229 & 474,591 & 14712,327 & 8,503 & 263,585 \\
\hline Agosto & 1424,529 & 44160,412 & 565,470 & 17529,568 & 10,131 & 314,058 \\
\hline Setembro & 1514,279 & 45428,377 & 601,096 & 18032,890 & 10,769 & 323,076 \\
\hline Outubro & 1713,944 & 53132,261 & 680,354 & 21090,963 & 12,189 & 377,864 \\
\hline Novembro & 1938,230 & 58146,911 & 769,385 & 23081,539 & 13,784 & 413,527 \\
\hline Dezembro & 2018,131 & 62562,075 & 801,102 & 24834,147 & 14,352 & 444,926 \\
\hline Total & 19081,62 & 580137,17 & 7574,49 & 230286,67 & 135,70 & 4125,80 \\
\hline Média & 1590,14 & 48344,76 & 631,21 & 19190,56 & 11,31 & 343,82 \\
\hline
\end{tabular}

FONTE: Elaborado pelos autores, 2018.

Segundo a Tabela 4, depreende-se que a geração de energia solar é maior nos meses mais quentes do ano, tendo em vista a maior incidência de sol sobre a região. $\mathrm{O}$ excesso de energia retorna à rede elétrica através do relógio de luz (bi-direcional) gerando créditos para a OM. Estes créditos são usados no momento em que não se produz energia, como no período da noite ou nos meses de menor produção do sistema. Cabe ressaltar que é principalmente nos meses mais quentes do ano que a bandeira tarifária se encontra na situação vermelha, isso se deve as estiagens associadas ao fato de no sul do Brasil a produção de energia ser prioritariamente feita por hidroelétricas. O próximo passo foi verificar a economia mensal e anual projetada após a instalação dos três projetos, conforme Tabela 5 .

TABELA 5 - Economia na fatura de energia elétrica mensal projetada

\begin{tabular}{|l|c|c|c|}
\hline & Projeto 1- OM 13 & $\begin{array}{c}\text { Projeto 2 } \\
\text { OM 1 }\end{array}$ & $\begin{array}{c}\text { Projeto 3 } \\
\text { OM 18 }\end{array}$ \\
\hline Custo do kWh & $\mathrm{R} \$ 0,3802$ & $\mathrm{R} \$ 0,3802$ & $\mathrm{R} \$ 0,3802$ \\
\hline Demanda mensal & $48344,76 \mathrm{kWh}$ & $19190,56 \mathrm{kWh}$ & $343,82 \mathrm{kWh}$ \\
\hline $\begin{array}{l}\text { Economia mensal } \\
\text { projetada (Retorno) }\end{array}$ & $\mathrm{R} \$ 18.380,68$ & $\mathrm{R} \$ 7.296,25$ & $\mathrm{R} \$ 130,72$ \\
\hline $\begin{array}{l}\text { Economia anual } \\
\text { projetada (Retorno) }\end{array}$ & $\mathrm{R} \$ 220.568,13$ & $\mathrm{R} \$ 87.555,01$ & $\mathrm{R} \$ 1.568,64$ \\
\hline
\end{tabular}

FONTE: Elaborado pelos autores, 2018. 
Ao considerar um custo médio de $\mathrm{R} \$ 0,3802$ por $\mathrm{kWh}$ que corresponde à média entre o horário de ponta e fora de ponta, dentro das bandeiras tarifárias vigentes e dos consumos dos meses de setembro e outubro de 2017, juntamente com os valores totais pagos na fatura, e uma possibilidade de geração média mensal de 48344,76 kWh, 19190,56 kWh e 343,82 kWh, é possível, de acordo com a Tabela 5, economizar anualmente R \$220.568,13, R\$ 87.555,01 e R \$ 1.568,64 em moeda corrente, ou seja, mensalmente R \$ 18.380,68 no Projeto 1, no Projeto 2 R \$ 87.555,01 e no Projeto 3 R\$ 1.568,64. Em posse dos custos para instalação e da economia total anual nas faturas procede-se aos cálculos de viabilidade econômica cujos resultados são apresentados na Tabela 6.

TABela 6 - Cálculo do payback descontado para os Projetos

\begin{tabular}{|c|c|c|c|c|c|c|}
\hline \multirow[b]{2}{*}{ Ano } & \multicolumn{2}{|c|}{$\begin{array}{c}\text { Projeto } 1 \text { - OM } 13 \\
\text { Investimento - } \mathrm{R} \$ 1.890 .060,00\end{array}$} & \multicolumn{2}{|c|}{$\begin{array}{c}\text { Projeto } 2 \text { - OM } 1 \\
\text { Investimento - R\$ 753.300,00 } \\
\end{array}$} & \multicolumn{2}{|c|}{$\begin{array}{c}\text { Projeto } 3 \text { - OM } 18 \\
\text { Investimento } \mathrm{R} \$ 17.550,00 \\
\end{array}$} \\
\hline & $\begin{array}{l}\text { Fluxo de caixa } \\
\text { Descontado } \\
\text { (R\$) }\end{array}$ & $\begin{array}{c}\text { Payback } \\
\text { Descontado (R\$) }\end{array}$ & $\begin{array}{c}\text { Fluxo de caixa } \\
\text { Descontado } \\
\text { (R\$) }\end{array}$ & $\begin{array}{c}\text { Payback } \\
\text { Descontado (R\$) }\end{array}$ & $\begin{array}{c}\text { Fluxo de caixa } \\
\text { Descontado } \\
\text { (R\$) }\end{array}$ & $\begin{array}{c}\text { Payback } \\
\text { Descontado } \\
\text { (R\$) }\end{array}$ \\
\hline 0 & & $-1.890 .060,00$ & & $-753.300,00$ & & $-17.550,00$ \\
\hline 1 & $205.370,70$ & $-1.684 .689,30$ & $81.517,70$ & $-671.782,30$ & $1.460,56$ & $-16.089,44$ \\
\hline 2 & $191.220,39$ & - 1.493.468,91 & $75.901,02$ & $-595.881,28$ & $1.359,92$ & $-14.729,52$ \\
\hline 3 & $178.045,06$ & $-1.315 .423,85$ & $70.671,34$ & $-525.209,94$ & $1.266,22$ & $-13.463,30$ \\
\hline 4 & $165.777,52$ & $-1.149 .646,33$ & $65.802,00$ & - 459.407,94 & $1.178,98$ & $-12.284,32$ \\
\hline 5 & $154.355,23$ & $-995.291,10$ & $61.268,05$ & $-398.139,89$ & $1.097,75$ & $-11.186,57$ \\
\hline 6 & $143.719,96$ & - 851.571,14 & $57.046,70$ & - 341.093,19 & $1.022,11$ & $-10.164,46$ \\
\hline 7 & $133.817,46$ & $-717.753,68$ & $53.116,11$ & - 287.977,08 & 951,69 & $-9.212,77$ \\
\hline 8 & $124.597,27$ & $-593.156,41$ & $49.456,34$ & - 238.520,74 & 886,11 & $-8.326,66$ \\
\hline 9 & $116.012,35$ & - 477.144,06 & $46.048,73$ & - 192.472,01 & 825,06 & $-7.501,60$ \\
\hline 10 & $108.018,95$ & -R369.125,11 & $42.875,91$ & $-149.596,10$ & 768,21 & $-6.733,39$ \\
\hline 11 & $100.576,30$ & $-268.548,81$ & $39.921,71$ & - 109.674,39 & 715,28 & $-6.018,11$ \\
\hline 12 & $93.646,46$ & $-174.902,35$ & $37.171,05$ & $-72.503,34$ & 666,00 & $-5.352,11$ \\
\hline 13 & $87.194,10$ & $-87.708,25$ & $34.609,92$ & $37.893,42$ & 620,11 & $-4.732,00$ \\
\hline 14 & $81.186,31$ & $-6.521,94$ & $32.225,25$ & $5.668,17$ & 577,38 & $-4.154,62$ \\
\hline
\end{tabular}




\begin{tabular}{|c|c|c|c|c|c|c|}
\hline 15 & $75.592,47$ & $69.070,53$ & $30.004,89$ & $24.336,72$ & 537,60 & $-3.617,02$ \\
\hline 16 & $70.384,05$ & $139.454,58$ & $27.937,51$ & $52.274,23$ & 500,56 & $-3.116,46$ \\
\hline 17 & $65.534,50$ & $204.989,08$ & $26.012,58$ & $78.286,81$ & 466,07 & $-2.650,39$ \\
\hline 18 & $61.019,09$ & $266.008,17$ & $24.220,28$ & $102.507,09$ & 433,96 & $-2.216,43$ \\
\hline 19 & $56.814,79$ & $322.822,96$ & $22.551,47$ & $125.058,56$ & 404,06 & $-1.812,37$ \\
\hline 20 & $52.900,18$ & $375.723,14$ & $20.997,64$ & $146.056,20$ & 376,22 & $-1.436,15$ \\
\hline 21 & $49.255,29$ & $424.978,43$ & $19.550,88$ & $165.607,08$ & 350,29 & $-1.085,86$ \\
\hline 22 & $45.861,53$ & $470.839,96$ & $18.203,80$ & $183.810,88$ & 326,16 & $-759,70$ \\
\hline 23 & $42.701,61$ & $513.541,57$ & $16.949,53$ & $200.760,41$ & 303,69 & $-456,01$ \\
\hline 24 & $39.759,42$ & $553.300,99$ & $15.781,69$ & $216.542,10$ & 282,76 & $-173,25$ \\
\hline 25 & $37.019,94$ & $590.320,93$ & $14.694,31$ & $231.236,41$ & 263,28 & 90,03 \\
\hline VPL(R\$)/TIR & 590.320, & $10,76 \%$ & $231.236,41$ & $10,71 \%$ & 20,03 & $7,46 \%$ \\
\hline
\end{tabular}

FONTE: Elaborado pelos autores, 2018

Os resultados da Tabela 6 demonstram que o Projeto 1, referente a OM13, dotado de um investimento inicial de R\$ 1.890.06o,oo precisaria 14 anos, 1 mês e 1 dia para obter retorno. O valor presente líquido ao final do vigésimo quinto ano será de $R$ \$590.320,93 e a taxa interna de retorno de 10,76\%. Observa-se, ainda, que ao final 9 anos a economia acumulada ( $\mathrm{R}$ \$ 220.568,13,45 x 9), é R \$ 95.053,17 superior ao custo total da instalação. Após os 25 anos analisados, em valores totais, o payback descontado mostra um retorno de $\mathrm{R} \$ 590.320,93$ evidenciando que o investimento cobre também os custos de manutenção, que se faz por volta de 10 a $15 \%$ do valor inicial (R $\$ 189.006,00$ a $R$ \$ 283.509,00). A partir da TIR de $10,76 \%$, estima-se que este projeto renda 3,36\% acima da Taxa Selic.

No que se refere ao Projeto 2 referente a OM 1, cujo investimento inicial é de R\$753.300,00, a TIR de 10,71\%, 3,31\% mais rentável que a Taxa Selic sugere a viabilidade para o período analisado, corroborada pelo VPL de R\$231.236,41 ao final do vigésimo quinto ano. Através do cálculo do payback descontado são necessários 14 anos, 2 meses e 8 dias para recuperar o investimento inicial. A economia acumulada durante um período de 9 anos ( $\mathrm{R} \$ 87.555,01$ x 9) identifica um valor total de $\mathrm{R}$ \$ 787.995,09, ou seja, R \$34.695,09 superior ao custo total da instalação do sistema de geração solar. Portanto, a partir de, aproximadamente, 8 anos, 7 meses e 7 dias o Projeto 2 também estará totalmente pago e gerando R $\$ 87.555,01$ de economia anual em energia elétrica. Em valores totais, o payback descontado remete a cobertura dos custos de manutenção no final do período analisado, com um retorno de até $\mathrm{R} \$ 234.236,41$, após os 25 anos de vida útil do sistema. 
Por fim, para o Projeto 3 da OM 18 com um investimento de R\$ 17.550,oo foi obtida uma TIR de 7,46\%, cerca de 0,06\% mais rentável que a Taxa Selic, o que é uma margem estreita. Por meio do payback descontado verifica-se que são necessários 24 anos, 7 meses e 27 dias para recuperar o investimento inicial. O VPL ao final do vigésimo quinto é R\$90,03, apesar de positivo não cobre os custos com manutenção mostrando que provavelmente deverá haver maior dispêndio de recursos para este fim. A análise se encerra com as projeções referentes a redução de emissão de poluentes, conforme Tabela7.

TABela 7 - Redução de gases poluentes dos Projetos 1, 2 e 3

\begin{tabular}{|c|c|c|c|}
\hline $\begin{array}{c}\text { Produção Termo Elétrica } \\
\text { Equivalente } \\
\text { (valores anuais) }\end{array}$ & Projeto 1 & Projeto 2 & Projeto 3 \\
\hline Dióxido de enxofre (SO2) & $406,58 \mathrm{~kg}$ & $161,39 \mathrm{~kg}$ & $2,89 \mathrm{~kg}$ \\
\hline Óxidos de Nitrogênio (NOx) & $511,83 \mathrm{~kg}$ & $203,17 \mathrm{~kg}$ & $3,64 \mathrm{~kg}$ \\
\hline Poeiras & $18,16 \mathrm{~kg}$ & $7,21 \mathrm{~kg}$ & $0,13 \mathrm{~kg}$ \\
\hline Dióxido de carbono (CO2) & $302,56 \mathrm{t}$ & $120,10 \mathrm{t}$ & $2,15 \mathrm{t}$ \\
\hline
\end{tabular}

FONTE: Elaborado pelos autores a partir dos dados da pesquisa, 2018.

A Tabela 7 descrimina a projeção do total de redução anual para as OM's após o sistema fotovoltaico entrar em funcionamento. Os valores apresentados são comparados em relação produção de energia via instalações termoelétricas, processo de geração de energia majoritário no Brasil, que se dá a partir da queima de combustíveis fósseis (diesel, carvão, mineral, gás natural, gasolina, etc). Percebe-se que com a utilização de um sistema fotovoltaico, há nítida diminuição de emissão de poluentes em relação a utilização de fontes termoelétricas, o que evidencia a contribuição positiva para o meio ambiente e gestão ambiental dos projetos instalados, atestando a sustentabilidade dos mesmos.

\section{CONSIDERAÇÕES FINAIS}

De acordo com a tendência mundial em buscar fontes de energia que sejam limpas, sustentáveis, e mais baratas, a cada dia são desenvolvidas e pesquisadas tecnologias inovadoras com o intuito de reduzir os danos causados pela geração de energia elétrica de maneira convencional. Uma alternativa a energia elétrica é a geração via sistemas de coletores de energia solar. Proveniente da luz e do calor do sol, a energia que o país recebe através da radiação solar, dentre as fontes de energias renováveis, destaca-se por ser autônoma, por não poluir o meio ambiente, por ser uma fonte inesgotável, renovável, e de grande confiabilidade. Outra vantagem associada a energia solar diz respeito a redução dos custos com consumo de energia elétrica no longo prazo (DUTRA et al., 2013).

Atento as atuais exigências sustentáveis e preocupado com a política ambiental o Organizações Militares vem desenvolvendo e apoiando o emprego de tecnologias limpas no intuito de diminuir o impacto sobre a natureza e promover uma economia de gastos públicos. Nesse 
sentido, o presente estudo se propôs a levantar gastos com energia elétrica, analisar a viabilidade da implantação do sistema fotovoltaico em termos de redução de gasto de recursos públicos bem como redução de poluentes emitidos para atmosfera. Os resultados indicam que apesar do custo inicial de instalação do projeto fotovoltaico ser bastante elevado, a redução de despesas com energia elétrica no longo prazo se mostrou bastante atraente principalmente nas OM's cuja demanda por energia elétrica é maior ou intermediária. $\mathrm{Na}$ OM's cujo gasto com energia elétrica é o menor, naturalmente obteve-se menores projeções nas reduções de despesas.

No que se refere ao estudo da viabilidade econômica constatou-se mediante projeções de fluxo de caixa e demonstrativos de resultado, que os investimentos são atraentes. Do ponto de vista da TIR e do VPL as três instalações demostram retorno positivo. No entanto, para a análise via payback descontados, que leva em consideração a desvalorização da moeda através do tempo, um dos projetos, o projeto de menor valor, reportou uma margem de retorno pequena ainda que positiva. Para esse mesmo projeto o tempo de retorno através do fluxo descontado foi praticamente o mesmo do período considerado para investimento, o que não o torna inviável do ponto de vista financeiro, mas não oferece vantagens econômicas se comparado com sistemas regulares. A despeito disso, os outros dois projetos deram sinais de que o investimento além de viável é rentável.

Dessa forma o estudo sugere que, os três projetos possibilitam retornos econômico positivos se levados em consideração a redução das despesas de energia elétrica, ajudando a resolver o problema da escassez energética e contribuindo para melhor alocação de recursos financeiros escassos, como é o caso das verbas públicas. Outra importante vantagem detectada diz respeito à redução de poluentes que a utilização de energia solar proporciona quando comparada a energias provenientes da queima de combustíveis fosseis. Assim, a instalação de projetos voltados à utilização de energia solar via placas fotovoltaicas é uma alternativa de fonte renovável para energia elétrica que atua consistentemente na redução de emissão de poluentes. Estudos futuros podem avaliar os ganhos financeiros e ambientais em outras organizações, tanto públicas quanto privadas. Entende-se que a implantação de energias renováveis em organizações públicas, bem como a criação de benefícios fiscais e incentivos para que as famílias brasileiras construam casas mais sustentáveis seriam estratégias eficientes para que o Brasil, utilizando a sua ampla fonte de energias renováveis, possa assumir papel de destaque no cenário mundial. 


\section{REFERÊNCIAS}

ABINEE, June. Propostas para inserção da energia solar fotovoltaica na matriz elétrica brasileira. Site da Associação Brasileira da Indústria Elétrica e Eletrônica. Avaible in http:// www. abinee. org. br/informac/arquivos/profotov. pdf, 2012.

ABRAMOVAY, Ricardo. Desenvolvimento sustentável: qual a estratégia para o Brasil?. Novos estudos-CEBRAP, n. 87, p. 97-113, 2010.

ASSAF NETO, Alexandre. Finanças corporativas e valor. São Paulo: Atlas, 2003.

AGÊNCIA NACIONAL DE ENERGIA ELÉTRICA- ANEEL. Resolução Normativa n. 482, de 17 de abril de 2012. Estabelece as condições gerais para o acesso de microgeração e minigeração distribuída aos sistemas de distribuição de energia elétrica, o sistema de compensação de energia elétrica. Rio de Janeiro, 2012. Disponível em <http://www. aneel.gov.br/cedoc/ren2012482.pdf>. Acesso: em 24 jun. 2017.

BRASIL. Portaria n.1.138-CmtEx, de 22 de novembro de $2010-$ Estabelece a Política de Gestão Ambiental do Exército Brasileiro

CASARO, Marcio Mendes; MARTINS, Denizar Cruz. Processamento eletrônico da energia solar fotovoltaica em sistemas conectados à rede elétrica. Revista Controle \& Automação, v. 21, n. 2, p. 159-172, 2010.

DOS SANTOS, Talía Simões et al. Análise da eficiência energética, ambiental e econômica entre lâmpadas de LED e convencionais. Eng Sanit Ambient, v. 20, n. 4, p. 595-602, 2015.

DUTRA, José Carlos do Nascimento et al. Uma Análise do Panorama das Regiões Missões e Noroeste do Estado do Rio Grande do Sul sob o Prisma da Energia Eólica e Solar Fotovoltaica como Fontes Alternativas de Energia. Revista Paranaense de Desenvolvimento-RPD, v. 34, n. 124, p. 225-243, 2013.

ELETROPAULO, AES. Bandeiras tarifárias. Disponível em:

$<$ https://www.aeseletropaulo.com.br/PublishingImages/ bandeiras-tarifarias.jpg>. Acesso em: 31 out. 2017.

ESPOSITO, Alexandre Siciliano; FUCHS, Paulo Gustavo. Desenvolvimento tecnológico e inserção da energia solar no Brasil. Revista do BNDES, Rio de Janeiro, n. 40, p. 85-113, 2013. GIL, Antonio Carlos. Como elaborar projetos de 
pesquisa. São Paulo, v. 5, n. 61, p. 16-17, 2002.

GRÄTZEL; 2001 Photoelectrochemical

cells . Nature 2001, 114-338.

GREENPEACE. Greenpeace Brasil. Aquarela energética, 2012. Disponível em:

$<$ http://www.greenpeace.org/brasil/Global/brasil/

image/2012/Maio/Aquarela\%2oEnerge \%cc

\%81tica.pdf $>$. Acesso em: 16 jun. 2017.

HIRSCHFELD, Henrique. Engenharia econômica

e análise de custos: aplicações práticas para

economistas, engenheiros, analistas de investimentos e administradores. 7. ed.5. reimp. São Paulo: Atlas, 2009.

HOUGHTON, John; JENKINS, Geoffrey; EPHRAUMS, J.

IPCC First Assessment Report 1990, Scientific Assessment of Climate Change: Report of Working Group 1.1990.

INSTITUTO BRASILEIRO DE PETRÓLEO, GÁS E BIOCOMBUSTÍVEIS - IBP. Crescimento da produção de petróleo na América Latina, 2016. Disponível em:

$<$ https://www.ibp.org.br/observatorio-do-setor/ crescimento-da-producao-de-petroleo-naamerica-latina/>. Acesso em: 18 jul. 2017.

MARCONI, Marina de Andrade; LAKATOS, Eva Maria. Técnicas de pesquisa: planejamento e execução de pesquisas, amostragens e técnicas de pesquisa, elaboração, análise e interpretação de dados. In: Técnicas de pesquisa: planejamento e execução de pesquisas, amostragens e técnicas de pesquisa, elaboração, análise e interpretação de dados. 2011.

PATERNIANI, José Euclides Stipp et al. Desinfecção de efluentes com tratamento terciário utilizando energia solar (SODIS): avaliação do uso do dispositivo para concentração dos raios solares. Engenharia Sanitária e Ambiental, 2005.

YIN, Robert et al. Estudo de caso: planejamento e métodos. Porto Alegre: Bookman, 2005.

ROSA, Victor Hugo da Silva. Energia elétrica renovável em pequenas comunidades no Brasil: em busca de um modelo sustentável. 2010.

SILVA, Rutelly Marques da. Energia solar no Brasil: dos incentivos ao desafios. 2015. 
SOLARIS, Brasil. Implantação de um sistema fotovoltaico, 2015. Disponível em:

$<$ http://solarisbrazil.com.br/?p=735>. Acesso em: 16 jun. 2017.

SOUZA, Acilon Batista. Projetos de investimentos de capital: elaboração. Análise e Tomada de Decisão. São Paulo: Atlas, 2003.A. B. Projetos de investimentos de capital: elaboração, análise, tomada de decisão. São Paulo: Atlas, 2003.

VICHI, Flavio Maron et al. Energia, meio ambiente e economia: o Brasil no contexto mundial.

Química Nova, v. 32, n. 3, p. 757-767, 2009. 